Article

\title{
Fabrication and Characteristics of an nc-Si/c-Si Heterojunction MOSFETs Pressure Sensor
}

\section{Xiaofeng Zhao, Dianzhong Wen * and Gang Li}

Key Laboratory of Electronics Engineering, College of Heilongjiang Province, Major Laboratories of Integrated Circuits, Heilongjiang University, Harbin 150080, China; E-Mails: zxf80310@126.com (X.Z.); lig8-78@msn.com (G.L.)

* Author to whom correspondence should be addressed; E-Mail: wendianzhong@126.com; Tel.: +86-451-8660-8413.

Received: 12 March 2012; in revised form: 2 May 2012 / Accepted: 3 May 2012 /

Published: 14 May 2012

\begin{abstract}
A novel nc-Si/c-Si heterojunction MOSFETs pressure sensor is proposed in this paper, with four p-MOSFETs with nc-Si/c-Si heterojunction as source and drain. The four p-MOSFETs are designed and fabricated on a square silicon membrane by CMOS process and MEMS technology where channel resistances of the four nc-Si/c-Si heterojunction MOSFETs form a Wheatstone bridge. When the additional pressure is $\mathrm{P}$, the $\mathrm{nc}-\mathrm{Si} / \mathrm{c}-\mathrm{Si}$ heterojunction MOSFETs pressure sensor can measure this additional pressure $\mathrm{P}$. The experimental results show that when the supply voltage is $3 \mathrm{~V}$, length-width $(\mathrm{L}: \mathrm{W})$ ratio is 2:1, and the silicon membrane thickness is $75 \mu \mathrm{m}$, the full scale output voltage of the pressure sensor is $15.50 \mathrm{mV}$ at room temperature, and pressure sensitivity is $0.097 \mathrm{mV} / \mathrm{kPa}$. When the supply voltage and $\mathrm{L}: \mathrm{W}$ ratio are the same as the above, and the silicon membrane thickness is $45 \mu \mathrm{m}$, the full scale output voltage is $43.05 \mathrm{mV}$, and pressure sensitivity is $2.153 \mathrm{mV} / \mathrm{kPa}$. Therefore, the sensor has higher sensitivity and good temperature characteristics compared to the traditional piezoresistive pressure sensor.
\end{abstract}

Keywords: nc-Si/c-Si heterojunction; MOSFETs pressure sensor; MEMS technology; CMOS process 


\section{Introduction}

At present, the various types of pressure sensors used include piezoresistive pressure sensors, capacitance pressure sensors, piezoelectric pressure sensors, resonator pressure sensors, and vacuum microelectronic pressure sensors, etc. [1-5]. In recent years, researchers have made use of the effects of the additional pressure $P$ on channel resistance, gate capacitance $C_{o x}$, threshold voltage $V_{T}$, and channel carrier mobility $\mu_{\mathrm{n}}$ ( or $\mu_{\mathrm{p}}$ ), to design and fabricate MOSFET pressure sensors [6-11]. For instance, Yan et al. [12] proposed a kind of MOSFET pressure sensor in 2001. Li et al. [13] designed and fabricated an integrated pressure sensor with a stress sensitive MOS operational amplifier in 2001. Zhang et al. [14] proposed a novel MEMS pressure sensor with MOSFET in 2008. Jachowicz et al. [15] of the Warsaw University of Technology fabricated a pressure sensitive field effect transistor (PSFET) in 2002. Fernández-Bolanõs et al. [16] reported the fabrication and electrical characterization of a novel pressure sensor based on a suspension-gate MOSFET(SG-MOSFET) using a new polyimide process. Garcia et al. [17] designed a pressure sensitive differential amplifier, whose sensitivity was $1.29 \mathrm{mV} / \mathrm{kPa}$, and power was $3 \mu \mathrm{W}$. The main structure of the MOSFET pressure sensors is suspension gate structure, and differential structure of double tube, etc.

In order to improve the sensitive characteristics of the pressure sensor, and research the effects of supply voltage, membrane thickness and channel L:W ratio on the characteristics of the sensor, according to the piezoresistive effect, in this paper four p-MOSFETs using the nc-Si/c-Si heterojunction as source and drain, are designed and fabricated on a square silicon membrane by CMOS process and MEMS technology, and form a Wheatstone bridge with the four nc-Si/c-Si heterojunction MOSFETs channel resistances.

Figure 1. Mask layout of the nc-Si/c-Si heterojunction MOSFETs pressure sensor chip.

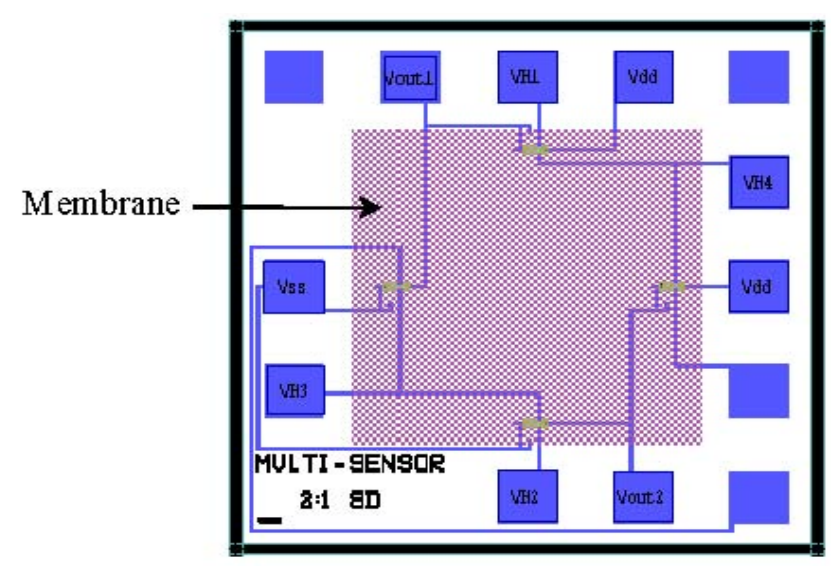

\section{Basic Structure and Operation Principle}

\subsection{Basic Structure}

Figure 1 shows the chip layout of the MOSFETs pressure sensor, where the MOSFETs take the nc$\mathrm{Si} / \mathrm{c}-\mathrm{Si}$ heterojunction as source and drain. In order to improve the sensitive characteristics of the pressure sensor, the nc-Si/c-Si heterojunction p-MOSFET is designed and fabricated on n-type $<100>$ orientation single crystal silicon wafer, which has been polished on both sides by a CMOS process and 
MEMS technology, and a Wheatstone bridge is composed of four nc-Si/c-Si heterojunction MOSFETs channel resistances, so that the measurement of the additional pressure $\mathrm{P}$ can be achieved. Figure 2 shows the schematic cross-section of the nc-Si/c-Si heterojunction MOSFETs pressure sensor chip.

Figure 2. Cross-section of the nc-Si/c-Si heterojunction MOSFETs pressure sensor chip.

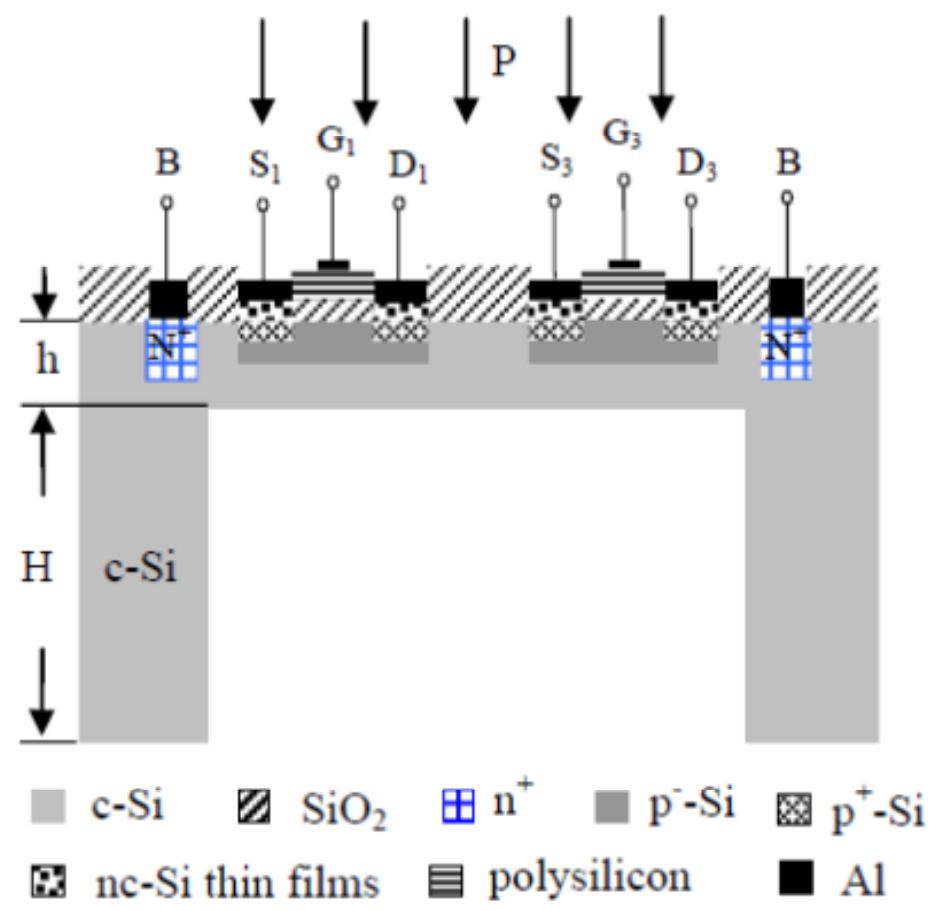

\subsection{Operation Principle}

Figure 3 shows operating principle schematic of the nc-Si/c-Si heterojunction MOSFETs pressure sensor. Figure 3(a) is the Wheatstone bridge structure composed of four nc-Si/c-Si heterojunction p-MOSFETs, which takes channel resistances $R_{1}, R_{2}, R_{3}$ and $R_{4}$ as piezoresistive resistances, Figure $3(b)$ is the equivalent circuit.

When the additional pressure $\mathrm{P}$ is zero, the output voltage $\mathrm{V}_{\text {OUT }}$ of the Wheatstone bridge is decided by four resistances $R_{1}, R_{2}, R_{3}, R_{4}$, and the constant bridge voltage $V_{D D}$, as given by Equation (1):

$$
V_{\text {OUT }}=V_{\text {OUT } 1}-V_{\text {OUT } 2}=\frac{R_{1} R_{3}-R_{2} R_{4}}{\left(R_{1}+R_{2}\right)\left(R_{3}+R_{4}\right)} V_{D D}
$$

If $R_{1}=R_{2}=R_{3}=R_{4}=R$, then:

$$
V_{\text {OUT }}=V_{\text {OUT1 }}-V_{\text {OUT2 }}=0
$$

When the additional pressure $\mathrm{P}$ isn't zero, channel resistances of the four nc-Si/c-Si heterojunction MOSFETs will change with the additional pressure $\mathrm{P}, \mathrm{V}_{\text {OUT }}$ of the Wheatstone bridge is given by Equation (3):

$$
V_{\text {OUT }}=V_{\text {OUT1 }}-V_{\text {OUT2 }}=\frac{\left(R_{1}+\Delta R_{1}\right)\left(R_{3}+\Delta R_{3}\right)-\left(R_{2}+\Delta R_{2}\right)\left(R_{4}+\Delta R_{4}\right)}{\left(R_{1}+\Delta R_{1}+R_{2}+\Delta R_{2}\right)\left(R_{3}+\Delta R_{3}+R_{4}+\Delta R_{4}\right)} V_{D D}
$$

If the variation of the channel resistances of the four nc-Si/c-Si heterojunction MOSFETs, are equal, as in the following Equation (4): 


$$
\Delta R_{1}=-\Delta R_{2}=\Delta R_{3}=-\Delta R_{4}=\Delta R
$$

Take Equation (4) into Equation (3), then:

$$
V_{\text {OUT }}=V_{\text {OUT1 }}-V_{\text {OUT } 2}=\frac{\Delta R}{R} V_{D D}
$$

$\mathrm{V}_{\text {OUT }}$ of the Wheatstone bridge is proportional to the relative variation $\Delta R / R$ of the channel resistance and supply voltage $\mathrm{V}_{\mathrm{DD}}$, respectively.

Figure 3. Operation principle of the nc-Si/c-Si heterojunction MOSFETs pressure sensor.

(a) Wheatstone bridge; (b) Equivalent circuit.

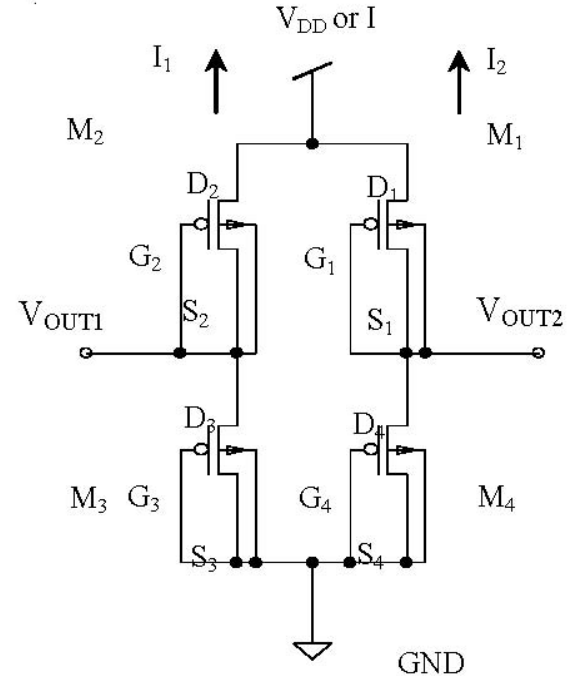

(a)

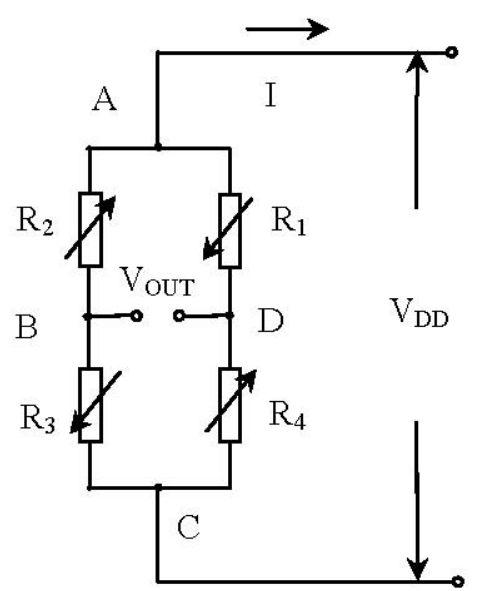

(b)

\section{Fabrication}

A nc-Si/c-Si heterojunction MOSFETs pressure sensor is proposed in this paper, which adopts ntype $<100>$ orientation single crystal silicon wafer with 4 -inch high resistance $(\rho>100 \Omega \cdot \mathrm{cm})$, which has been polished on both sides and its thickness is $450 \mu \mathrm{m}$, Figure 4 shows the main fabrication technology process of the MOSFETs pressure sensor chip. Figure 4(a) single crystal silicon wafer; Figure 4(b) first oxidation, and $\mathrm{SiO}_{2}$ growth by a thermal oxidation process; Figure 4(c) first lithography, lithography active region window; Figure 4(d) second oxidation, and $\mathrm{SiO}_{2}$ growth by a thermal oxidation process in order to improve the uniformity of ion implantation; Figure 4(e) ion implantation, B ions implantation by ion implantation machine to obtain p-type doping, injection energy $40 \mathrm{KeV}$, injection dose of $6.0 \times 10^{13}$; Figure $4(\mathrm{f})$ etching of $\mathrm{SiO}_{2}$ layer; Figure $4(\mathrm{~g})$ third oxidation, the growth of gate oxide layer with thickness of $50 \mathrm{~nm}$; Figure 4(h) growth of polysilicon gate by LPCVD and diffusion of phosphorus to the polysilicon gate; Figure 4(i) second lithography, lithographing polysilicon to form a polysilicon gate, and implantation of boron to form p-type doping for the source and drain of the MOSFET; Figure 4(j) third lithography; Figure 4(k) implantation of P, forming $\mathrm{N}^{+}$substrate; Figure 4(1) oxidation of polysilicon, growth of $\mathrm{SiO}_{2}$ layer by synthesis of oxidation of $\mathrm{H}_{2}$ and $\mathrm{O}_{2}$; Figure 4(m) forth lithography to form the source and drain of the MOSFET; Figure 4(n) fifth lithography to grow the nc-Si thin film by LPCVD; Figure 4(o) sixth lithography to 
make lead holes; Figure 4(p) magnetron sputtering positively aluminum layer to the single crystal silicon wafer as aluminum electrode, and sputtering aluminum layer on the back, as passivation layer of ICP etching silicon; Figure 4(q) etching of C-type silicon cup window; Figure 4(r) eighth lithography, etching C-type silicon cup window; Figure 4(s) by adopting an ALCATEL 601E type ICP, deep groove etching to make nc-Si/c-Si heterojunction MOSFETs pressure sensor chip with $6 \mathrm{~mm} \times 6 \mathrm{~mm}$ square silicon membranes of $75 \mu \mathrm{m}$ and $45 \mu \mathrm{m}$ thicknesses, respectively. The etch rate is about $4.5 \mu \mathrm{m} / \mathrm{min}$.

Figure 4. Fabrication technology process of the nc-Si/c-Si heterojunction MOSFETs pressure sensor chip.

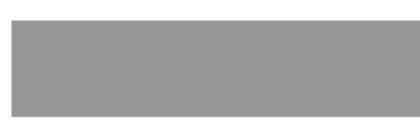

(a)

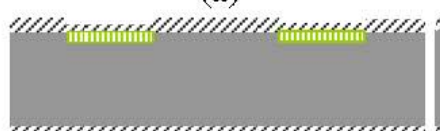

(e)

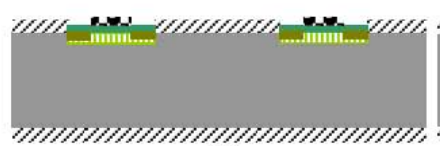

(i)

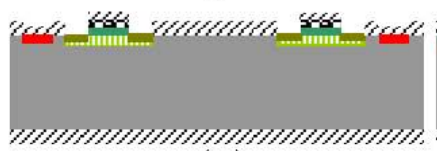

(m)

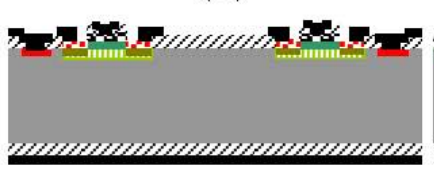

(q)

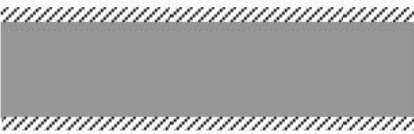

(b)

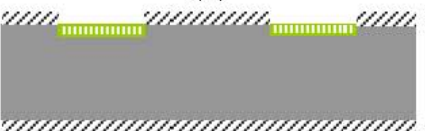

(f)

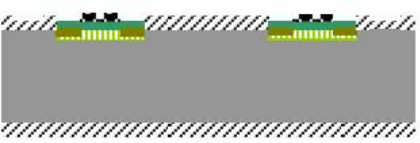

(j)

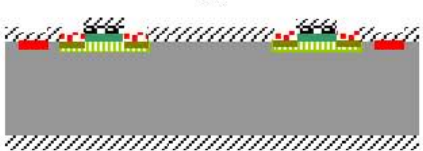

(n)

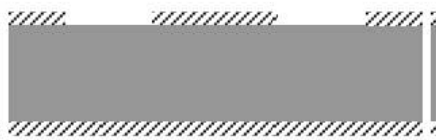

(c)

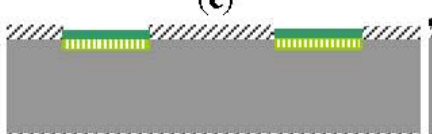

(g)

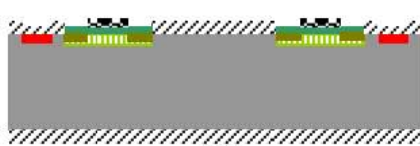

(k)

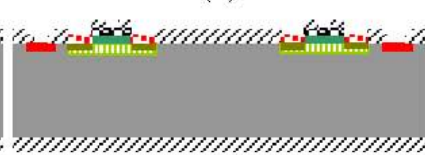

(o)

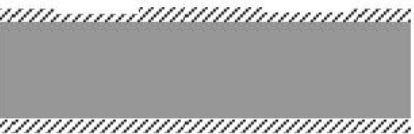

d)

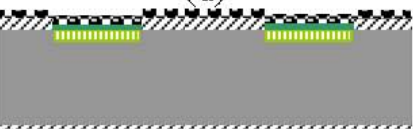

(h)

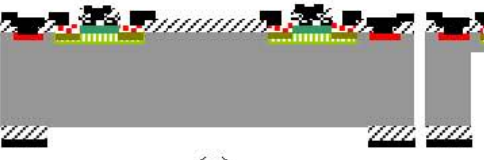

(r) (s)

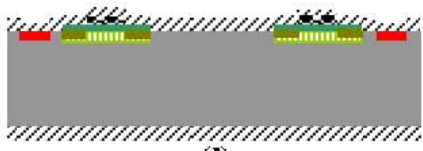

(I)

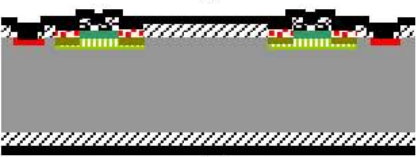

(p)

Figure 5. Photograph of the nc-Si/c-Si heterojunction MOSFETs pressure sensor chip with length-width ratio 2:1.

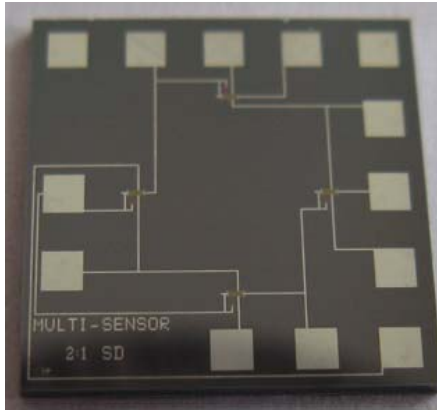

(a)

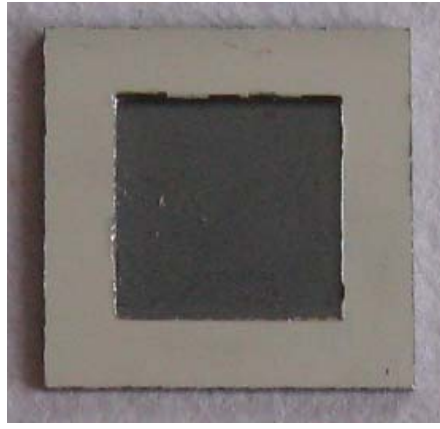

(b)

Figure 5 shows the photograph of the nc-Si/c-Si heterojunction MOSFETs pressure sensor chip with $\mathrm{L}: \mathrm{W}$ ratio $2: 1$ proposed in this paper. 


\section{Experimental Results and Discussion}

\subsection{Piezoresistance Characteristics}

Under the condition of an environmental temperature of $22{ }^{\circ} \mathrm{C}$, and relative humidity of $15 \% \mathrm{RH}$, the piezoresistance characteristics of the M1 channel resistance of pressure sensor, which includes the nc-Si/c-Si heterojunction MOSFETs with L:W ratio 2:1 and square silicon membrane thickness $45 \mu \mathrm{m}$, is measured by a Mensor PCS400 Pressure Calibration System, Figure 6 shows the $I_{D S}-V_{D S}$ characteristic curves of the nc-Si/c-Si heterojunction MOSFETs when the additional pressure $\mathrm{P}$ is $0 \mathrm{kPa}$ and $20 \mathrm{kPa}$, respectively.

Figure 6. When $P$ is constant, $I_{D S}-V_{D S}$ characteristics curves of the nc-Si/c-Si heterojunction MOSFETs.

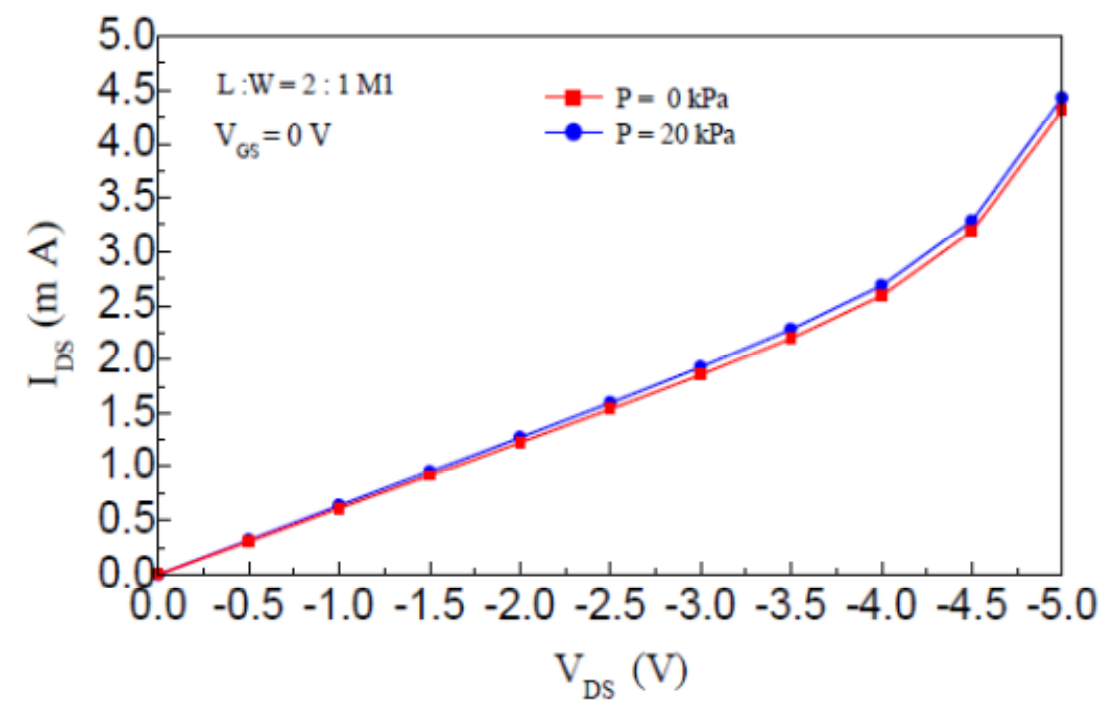

\subsection{Effect of Thickness of Silicon Membrane on Characteristics}

When the test environment temperature is $22{ }^{\circ} \mathrm{C}$, and relative humidity is $15 \% \mathrm{RH}$, calibration experiments of the nc-Si/c-Si heterojunction MOSFETs pressure sensor, which includes the nc-Si/c-Si heterojunction MOSFETs with L:W ratio 2:1 and square silicon membrane thickness $75 \mu \mathrm{m}$ and 45 $\mu \mathrm{m}$, respectively, are done using a Mensor PCS400 pressure calibration systems, HP34401A multimeter and BJ1790B power supply. The additional pressure range of the sensor with silicon membrane thickness $75 \mu \mathrm{m}$, are from 0 to $160 \mathrm{kPa}$, the additional pressure range of the sensor with silicon membrane thickness $45 \mu \mathrm{m}$, are from 0 to $20 \mathrm{kPa}$.

When the supply voltage $\mathrm{V}_{\mathrm{DD}}$ is $1.0 \mathrm{~V}, 1.5 \mathrm{~V}$ and $3.0 \mathrm{~V}$, respectively, Figure 7 shows the input-output characteristic experimental curves of the pressure sensor with channel L:W of 2:1 and silicon membrane thickness of $75 \mu \mathrm{m}$ and $45 \mu \mathrm{m}$, respectively. The experimental results show that, when the silicon membrane thickness is constant, the full scale output voltage of the sensor is proportional to the supply voltage. On the condition that the supply voltage is $3.0 \mathrm{~V}$, the full scale $(160 \mathrm{kPa})$ output voltage of the sensor is $15.50 \mathrm{mV}$ and the sensitivity of the pressure sensor is $0.097 \mathrm{mV} / \mathrm{kPa}$ when the silicon membrane thickness is $75 \mu \mathrm{m}$, and the full scale $(20 \mathrm{kPa})$ output voltage of the sensor is $43.05 \mathrm{mV}$, and sensitivity of the pressure sensor is $2.153 \mathrm{mV} / \mathrm{kPa}$ when the silicon membrane thickness 
is $45 \mu \mathrm{m}$. The experimental results show that the sensitivity of the nc-Si/c-Si heterojunction MOSFETs pressure sensor is inversely proportional to the silicon membrane thickness.

Figure 7. Input-output characteristics experimental curves of the nc-Si/c-Si heterojunction MOSFETs pressure sensor. (a) Membrane thickness $75 \mu \mathrm{m}$; (b) Membrane thickness $45 \mu \mathrm{m}$.

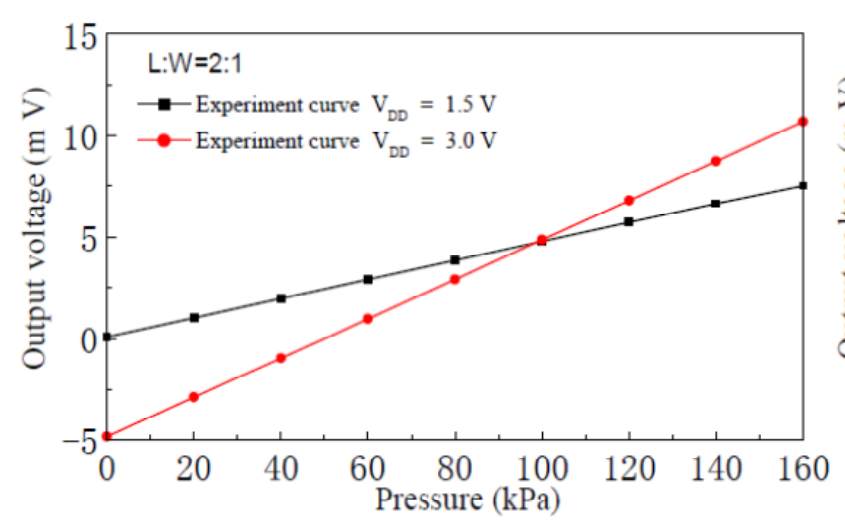

(a)

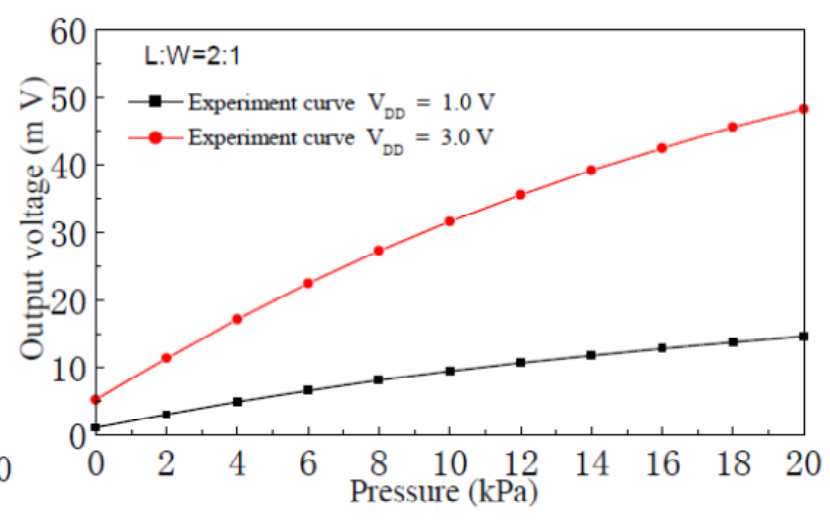

(b)

Figure $8(\mathrm{a}, \mathrm{b})$ shows fitting straight lines and experimental curves of the input-output characteristics of the pressure sensor with silicon membrane thicknesses of $75 \mu \mathrm{m}$ and $45 \mu \mathrm{m}$, respectively. When the supply voltage is $3.0 \mathrm{~V}$, linearity of the pressure sensor with silicon membrane thicknesses of $75 \mu \mathrm{m}$ and $45 \mu \mathrm{m}$, is $0.130 \%$ F.S and $7.73 \%$ F.S, respectively.

Figure 8. Input-output characteristics fitting beelines and experimental curves of the nc$\mathrm{Si} / \mathrm{c}-\mathrm{Si}$ heterojunction MOSFETs pressure sensor. (a) Membrane thickness $75 \mu \mathrm{m}$; (b) Membrane thickness $45 \mu \mathrm{m}$.

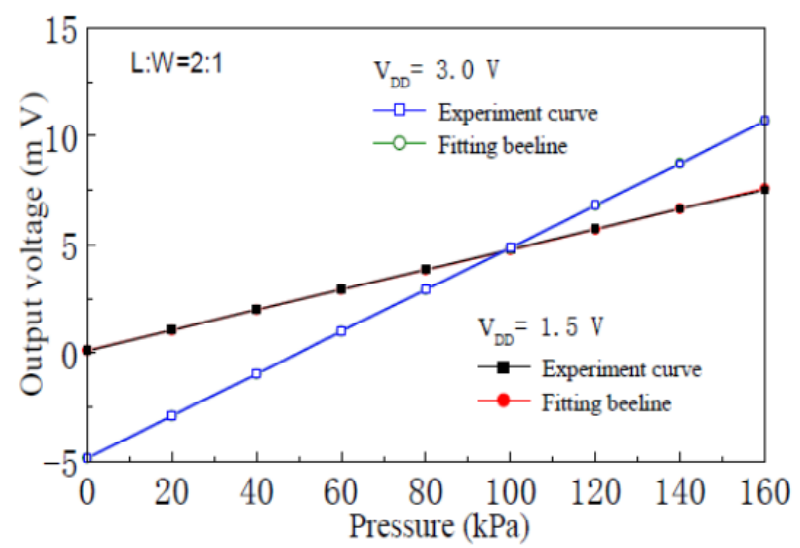

(a)

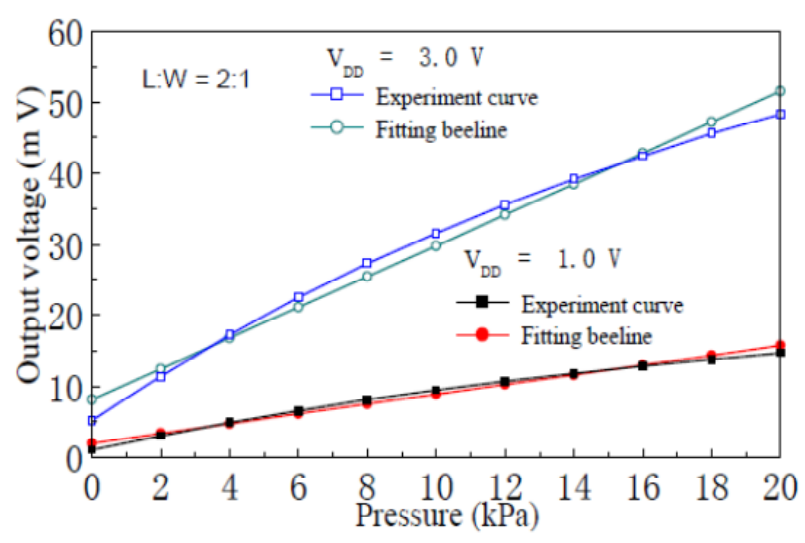

(b)

Figure $9(a, b)$ shows repeatability experimental curves of the pressure sensor with silicon membrane thickness of $75 \mu \mathrm{m}$ and $45 \mu \mathrm{m}$, respectively. When the supply voltage is $3.0 \mathrm{~V}$, repeatability of the pressure sensor with silicon membrane thicknesses of $75 \mu \mathrm{m}$ and $45 \mu \mathrm{m}$ is $0.66 \%$ F.S and $5.42 \%$ F.S, respectively. 
Figure 9. Repeatability experimental curves of the nc-Si/c-Si heterojunction MOSFETs pressure sensor. (a) Membrane thickness $75 \mu \mathrm{m}$; (b) Membrane thickness $45 \mu \mathrm{m}$.

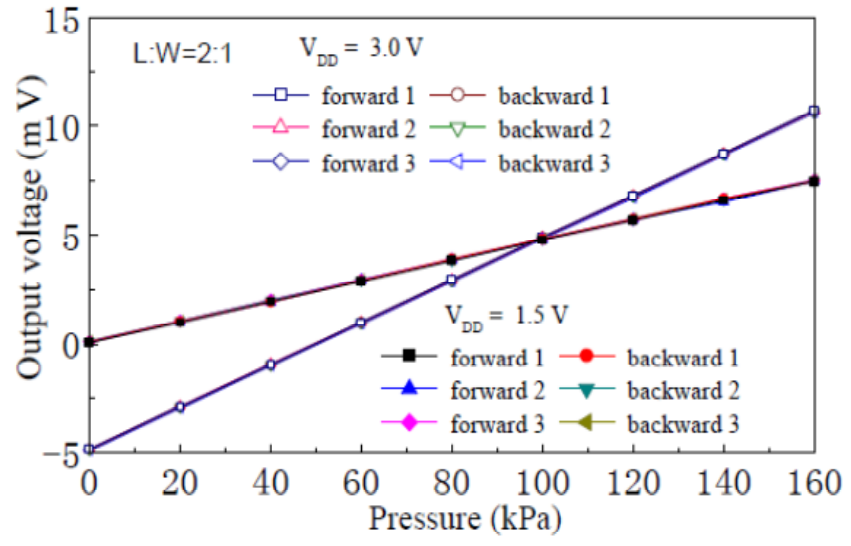

(a)

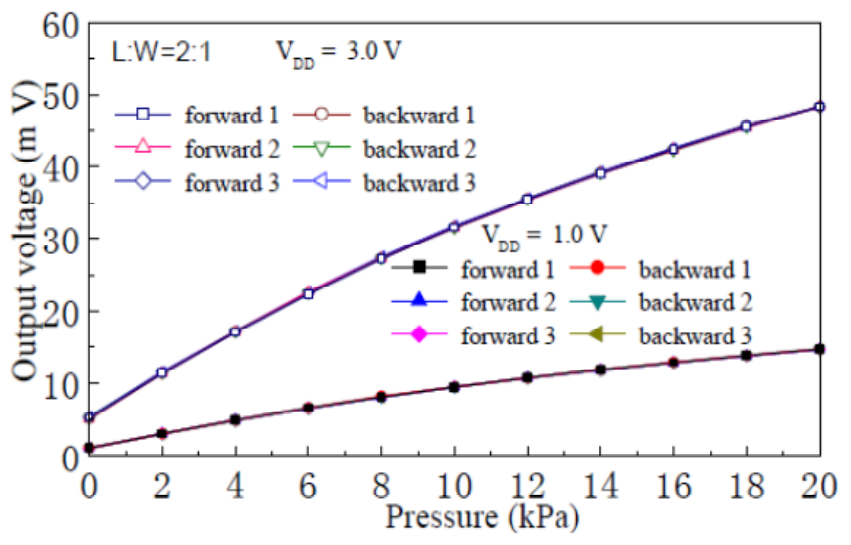

(b)

Figure 10(a,b) shows the hysteresis experimental curves of the pressure sensor with silicon membrane thicknesses of $75 \mu \mathrm{m}$ and $45 \mu \mathrm{m}$, respectively. When the supply voltage is $3.0 \mathrm{~V}$, hysteresis of the sensor with silicon membrane thicknesses of $75 \mu \mathrm{m}$ and $45 \mu \mathrm{m}$, is $0.15 \%$ F.S and $2.74 \%$ F.S, respectively.

Figure 10. Hysteresis experimental curves of the nc-Si/c-Si heterojunction MOSFETs pressure sensor. (a) Membrane thickness $75 \mu \mathrm{m}$; (b) Membrane thickness $45 \mu \mathrm{m}$.

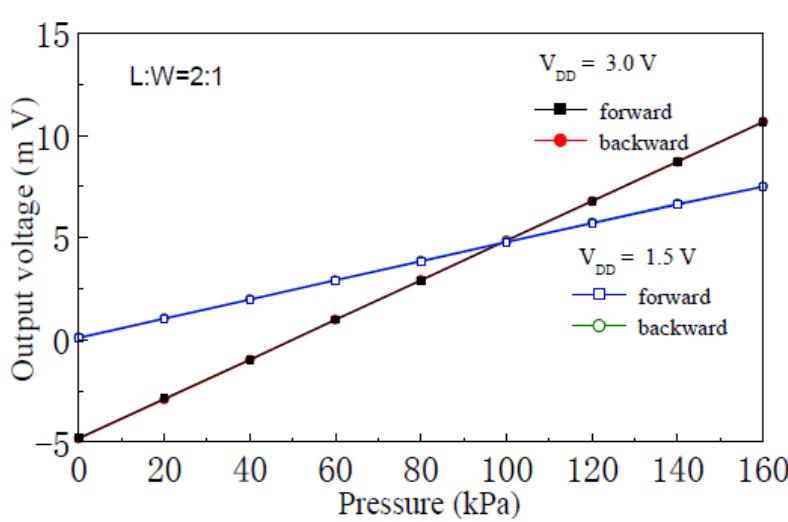

(a)

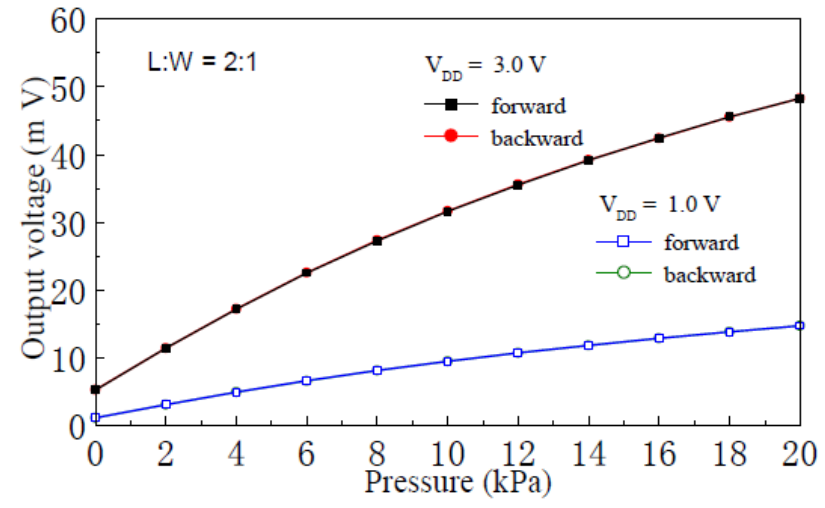

(b)

\subsection{Effect of Length-Width Ratio of the MOSFET Channel on Characteristics}

When the supply voltage is $1.5 \mathrm{~V}$, Figure 11 shows the input-output characteristic experimental curves of the pressure sensor with the nc-Si/c-Si heterojunction MOSFETs, which has a silicon membrane thickness $75 \mu \mathrm{m}$ and channel $\mathrm{L}: \mathrm{W}$ ratios of $2: 1$ and $6: 1$. The experimental results show that when the supply voltage is constant, the sensitivity of the nc-Si/c-Si heterojunction MOSFETs pressure sensor is proportional to $\mathrm{L}: \mathrm{W}$ ratio for the $\mathrm{nc}-\mathrm{Si} / \mathrm{c}-\mathrm{Si}$ heterojunction MOSFET channel. 
Figure 11. Input-output characteristics experimental curves of the nc-Si/c-Si heterojunction MOSFETs pressure sensor with different channel length-width ratios.

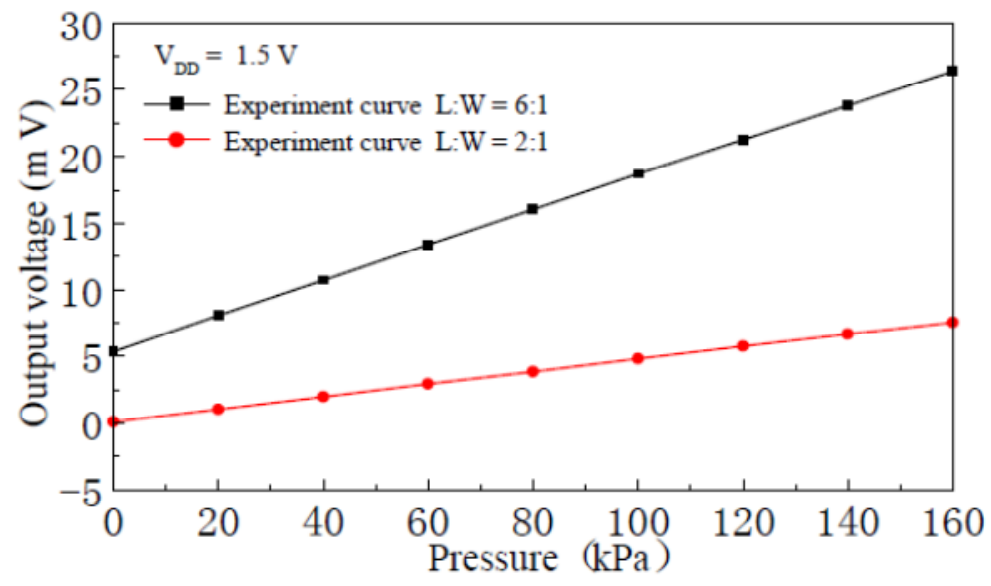

Figure 12. Input-output characteristics curves of the nc-Si/c-Si heterojunction MOSFETs pressure sensor at different temperatures.

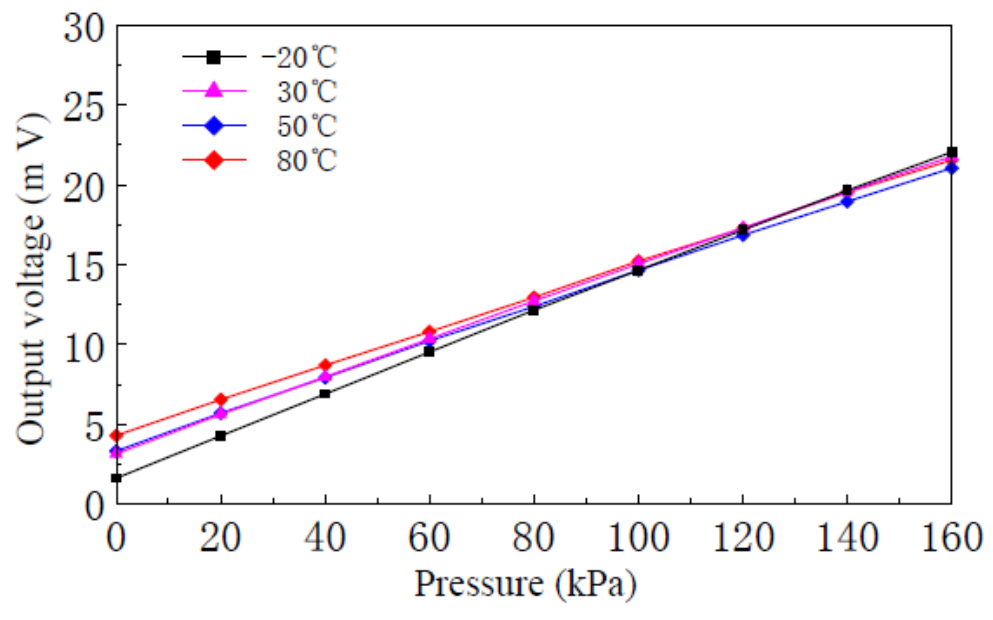

\subsection{Temperature Characteristics}

High and low temperature experiments are done from $-20{ }^{\circ} \mathrm{C}$ to $80{ }^{\circ} \mathrm{C}$ using a Shanghai Blue Leopard LGS-010C high and low temperature chamber. When the supply voltage is $1.5 \mathrm{~V}$, Figure 12 shows different temperature input-output characteristics experimental curves of the nc-Si/c-Si heterojunction MOSFETs pressure sensor with channel L:W ratio of 6:1. Zero temperature coefficient TCO:

$$
T C O=\frac{V_{0}\left(T_{2}\right)-V_{0}\left(T_{1}\right)}{V_{0}\left(T_{1}\right)\left(T_{2}-T_{1}\right)} \times 100 \%=16320 \mathrm{ppm} /{ }^{\circ} \mathrm{C}
$$

where $V_{0}\left(T_{1}\right)$ and $V_{0}\left(T_{2}\right)$ are the zero outputs of the sensor when the temperature is $\mathrm{T}_{1}$ and $\mathrm{T}_{2}$, respectively. Sensitivity temperature coefficient $T C S$ :

$$
T C S=\frac{\left[V_{F . S}\left(T_{2}\right)-V_{0}\left(T_{2}\right)\right]-\left[V_{F . S}\left(T_{1}\right)-V_{0}\left(T_{1}\right)\right]}{\left[V_{F . S}\left(T_{1}\right)-V_{0}\left(T_{1}\right)\right]\left(T_{2}-T_{1}\right)} \times 100 \%=-1550 \mathrm{ppm} /{ }^{\circ} \mathrm{C}
$$

where $V_{\mathrm{F} . S}\left(T_{1}\right)$ and $V_{\mathrm{F} . \mathrm{S}}\left(T_{2}\right)$ are the full scale outputs of the sensor when the temperature is $\mathrm{T}_{1}$ and $\mathrm{T}_{2}$, respectively. 


\section{Conclusions}

In order to measure the additional pressure $\mathrm{P}$, a MOSFET using a nc-Si/c-Si heterojunction as source and drain, is produced on high resistance single crystal silicon substrate with n-type $<100>$ orientation by CMOS process and MEMS technology, and a Wheatstone bridge structure is composed of four $\mathrm{nc-Si} / \mathrm{c}-\mathrm{Si}$ heterojunction MOSFETs. Full scale output voltage of the pressure sensor is proportional to the supply voltage. When the silicon membrane thickness is $75 \mu \mathrm{m}$, full scale (160 $\mathrm{kPa})$ output voltage of the pressure sensor is $15.50 \mathrm{mV}$ and sensitivity is $0.097 \mathrm{mV} / \mathrm{kPa}$ when the supply voltage is $3.0 \mathrm{~V}$. When the silicon membrane thickness is $45 \mu \mathrm{m}$, full scale (20 kPa) output voltage is $43.05 \mathrm{mV}$ and sensitivity is $2.153 \mathrm{mV} / \mathrm{kPa}$ when the supply voltage is $3.0 \mathrm{~V}$, so the sensitivity of the pressure sensor is inversely proportional to the silicon membrane thickness. When the silicon membrane thickness and supply voltage are constant, the sensitivity of the pressure sensor is proportional to the channel $\mathrm{L}: \mathrm{W}$ ratio. When the temperature varies from $-20{ }^{\circ} \mathrm{C}$ to $80{ }^{\circ} \mathrm{C}$, temperature coefficients of zero point and sensitivity of the nc-Si/c-Si heterojunction MOSFETs pressure sensor with channel $\mathrm{L}: \mathrm{W}$ ratio of $6: 1$, are $16,320 \mathrm{ppm} /{ }^{\circ} \mathrm{C}$ and $-1,550 \mathrm{ppm} /{ }^{\circ} \mathrm{C}$, respectively, so the $\mathrm{nc}-\mathrm{Si} / \mathrm{c}-\mathrm{Si}$ heterojunction MOSFETs pressure sensor has higher sensitivity and a lower temperature coefficient compared to traditional piezoresistive pressure sensors.

\section{Acknowledgements}

This work was supported by the National Natural Science Foundation of China (NSFC: 60676044 61006057), Foundation for University Young Key Teacher of Heilongjiang Province (1251G046), Excellent Youth Foundation of Heilongjiang University(JCL201007) and the Key Laboratory of Electronics Engineering of College of Heilongjiang Province (DZZD20100013).

\section{References}

1. Kanda, Y.; Yasukawa, A. Optimum design considerations for silicon piezoresistive pressure sensors. Sens. Actuat. A 1997, 62, 539-542.

2. Sun, Y.C.; Gao, Z.; Tian, L.Q.; Zhang, Y. Modelling of the reverse current and its effects on the thermal drift of the offset voltage for piezoresistive pressure sensors. Sens. Actuat. A 2004, 116, 125-132.

3. Pedersen, T.; Fragiacomo, G.; Hansen, O.; Thomsen, E.V. Highly sensitive micromachined capacitive pressure sensor with reduced hysteresis and low parasitic capacitance. Sens. Actuat. A 2009, 154, 35-41.

4. Catling, D.C. High-sensitivity silicon capacitive sensors for measuring medium-vacuum gas pressures. Sens. Actuat. A 1998, 64, 157-164.

5. He, F.; Huang, Q.-A.; Qin, M. A silicon directly bonded capacitive absolute pressure sensor. Sens. Actuat. A 2007, 135, 507-514.

6. Hynes, E.; Oneill, M.; McAuliffer, D.; Berney, H.; Lane, W.A.; Kelly, G.; Hill, M. Development and characterisation of a surface micromachined FET pressure sensor on a CMOS process. Sens. Actuat. A 1999, 76, 283-292. 
7. Bradley, A.T.; Jaeger, R.C.; Suhling, J.C.; O’Connor, K.J. Piezoresistive characteristics of short channel MOSFETs on (100) silicon. IEEE Trans. Electron. Devices 2001, 48, 2009-2015.

8. Vatedka, R.; Takao, H.; Sawada, K.; Ishida, M. Effect of high drain voltage on stress sensitivity in nMOSFETs. Sens. Actuat. A 2007, 140, 89-93.

9. Dai, C.L.; Kao, P.H.; Tai, Y.W.; Wu, C.C. Micro FET pressure sensor manufactured using CMOS-MEMS technique. Microelectron. J. 2008, 39, 744-749.

10. Sallese, J.-M.; Grabinski, W.; Meyer, V.; Bassin, C.; Fazan, P.Electrical modeling of a pressure sensor MOSFET. Sens. Actuat. A 2001, 94, 53-58.

11. Wen, D. Sensitivity analysis of junction field effect-pressure Halltron. Rev. Sci. Instrum. 1995, 66, 251-255.

12. Yan, H.; Feng, Y.; Xu, J.; Bian, J. MOS field effect transistor pressure microsensor. J. Transducer Technol. 2001, 5, 19-21.

13. Li, J.; Yue, R.; Liu, L. MOSFET Differential Amplifier with Input Pair and Active Load Pair being Stress-Sensitive Both. In Proceeding of 6th International IEEE Conference Solid State and Integrated Circuit Technology, Shanghai, China, 22-25 October 2001; Volume 2, pp. 812-815.

14. Zhang, Z.; Zhang, Y.; Liu, L.; Ren, T. A Novel MEMS Pressure Sensor with MOSFET on Chip. In Proceeding of IEEE Conference Sensors, Lecce, Italy, 26-29 October 2008; pp. 1564-1567.

15. Jachowicz, R.S.; Azgin, Z.M. FET pressure sensor and iterative method for modeling of the device. Sens. Actuat. A 2002, 97-98, 369-378.

16. Fernández-Bolaños, M.; Abelé, N.; Pott, V.; Bouvet, D.; Racine, G.-A.; Quero, J.M.; Ionescu, A.M. Polyimide sacrificial layer for SOI SG-MOSFET pressure sensor. Microelectron. Eng. 2006, 83, $1185-1188$.

17. Garcia, V.; Fruett, F. A mechanical-stress sensitive differential amplifier. Sens. Actuat. A 2006, $132,8-13$.

(C) 2012 by the authors; licensee MDPI, Basel, Switzerland. This article is an open access article distributed under the terms and conditions of the Creative Commons Attribution license (http://creativecommons.org/licenses/by/3.0/). 